\title{
Lysosome-mitochondria-mediated apoptosis specifically evoked in cancer cells induced by gold nanorods
}

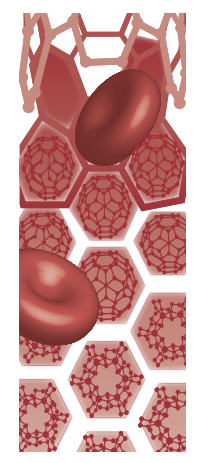

\begin{abstract}
Aim: The main aim of this article is to explain the apoptosis mechanisms of cancer cells specifically triggered by gold nanorods (GNRs). Materials \& methods: GNRs were synthesized and optimized, the lysosome damage, cathepsin $D$, mitochondrial membrane potential, caspase-9, cleaved caspase-9, caspase-3 and intracellular GNRs location related to apoptosis was systematically evaluated. Results: GNRs specifically induce cancer cell apoptosis while posing a negligible impact on normal cells. After incubation with GNRs, the lysosomal permeability in cancer cells as indicated by cathepsin D was markedly higher than that in normal cells and resulted in an obvious decrease in mitochondrial membrane potential. Western blot analysis further confirmed that apoptosis occurred through caspase- 9 and caspase-3 activation following mitochondrial damage. Transmission electron microscope images showed that GNRs did not appear in most of the damaged mitochondria but mainly accumulated in lysosomes. Conclusion: These findings indicated that GNR-induced apoptosis specifically in cancer cells by affecting lysosomes and mitochondria.
\end{abstract}

First draft submitted: 11 April 2016; Accepted for publication: 17 May 2016; Published online: 3 June 2016

Keywords: apoptosis $\bullet$ gold nanorods $\bullet$ lysosome $\bullet$ mitochondrion

Traditional chemotherapy improves the survival rate of cancer patients. However, the prognosis is poor due to the associated severe side effects. It is widely accepted that nanomedicine opens new platforms for cancer treatment that can overcome the above drawbacks through its high biocompatibility and stability during systemic circulation, prolonged periods of retention time in tumor sites and controlled drug release [1,2]. Nanomaterials include gold nanoparticles (NPs), carbon nanotubes, quantum dots, nanoclusters, nanogels, paramagnetic NPs and nanomicelles; the most extensively studied nanomaterials [3-10] have been used in clinical trials [11,12]. Gold nanorod (GNR) has the greatest potential due to its favorable and unique physiochemical properties, such as size, shape, aspect ratio, charge, surface groups and modifications [13-15]. GNRs are now widely used in biomedical fields, such as photothermal therapy of tumors, bioimaging, biosensing, $x$-ray computed tomography and drug-gene delivery [16-20].

The therapeutic effects of GNRs strongly depend on their extra-/intra-cellular location. For example, when GNRs are applied for plasmid (p)DNA or siRNA delivery, they should be maintained in the cytosol because efficient lysosomal escape is essential for gene function [21]. When GNRs are introduced for bioimaging modules, they should be trapped in vesicles with a long blood circulation time for production and strong signaling [22]. For promoting the biomedical applications of GNRs, it is better to disclose their intracellular uptake and fate. For most gold nanostructures, the internalization mechanism is considered receptormediated endocytosis (RME) [23]. During
Fulei Zhang ${ }^{\ddagger 1,}$, Xiandi Zhu ${ }^{\ddagger 1,}$, Jing Gong ${ }^{\ddagger, 2}$, Yun Sun', Di Chen', Jie Wang', Ying Wang ${ }^{1}$, Mengfang Guo' \& Wei $\mathrm{Li}^{*, 1,3}$

'International Joint Cancer Institute, The Second Military Medical University, Shanghai 200433, China

2Department of Radiology, The Second Military Medical University, First Affiliated, Hospital, 168 Changhai Road, Shanghai 200433, China 3PLA General Hospital Cancer Center, PLA Graduate School of Medicine, Beijing 100853, China

*Author for correspondence: Tel.:+862181870804 Fax: +862181870801 liwei@smmu.edu.cn ${ }^{\ddagger}$ Authors contributed equally

\section{Future 8 Medicine ${ }_{\text {part of }}$




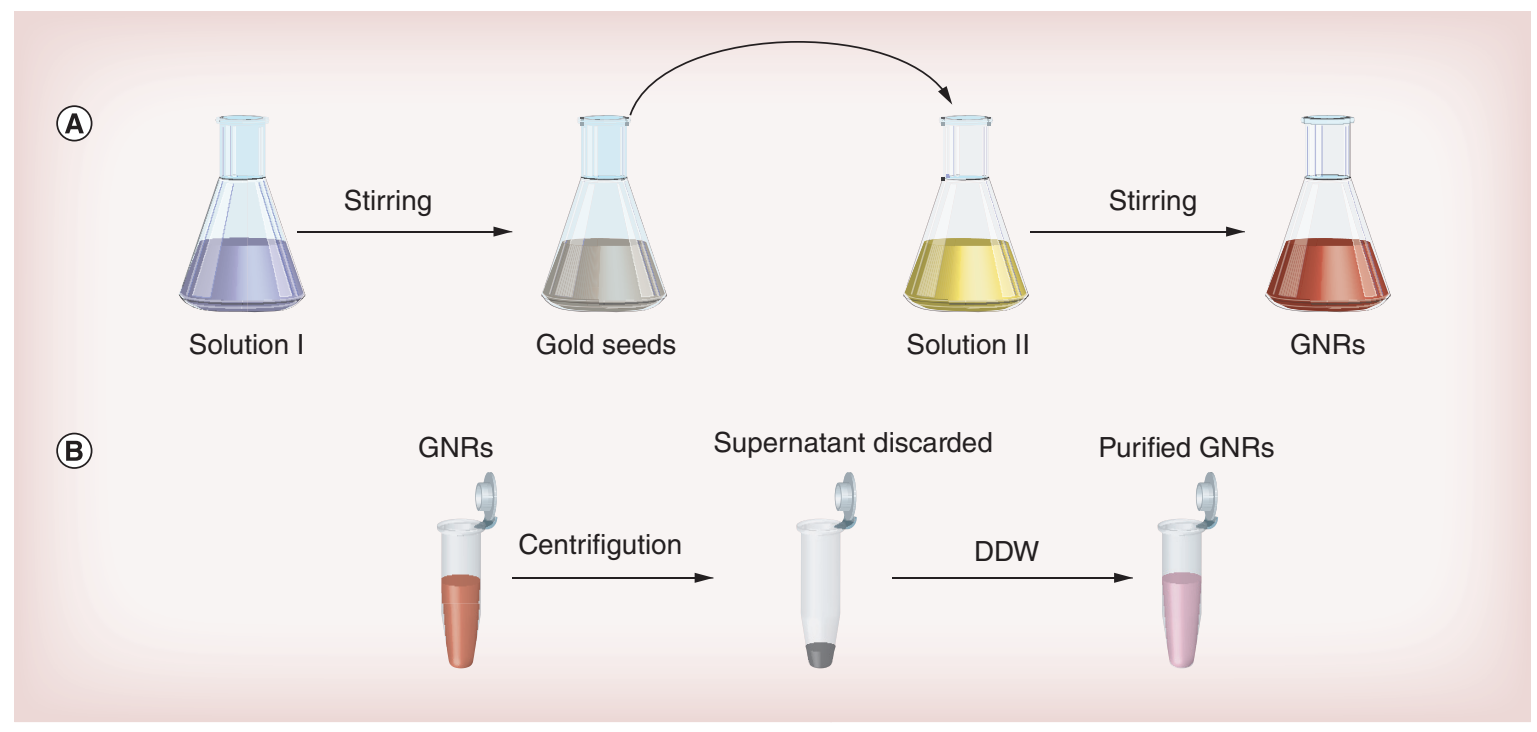

Figure 1. The synthesis process and purification procedure of gold nanorods. (A) GNRs were prepared by seededgrowth method. Solution I contained $0.2 \mathrm{~mol} / \mathrm{l}$ cetyltrimethyl ammonium bromide, $5 \times 10^{-4} \mathrm{~mol} / \mathrm{l}$ chloroauric acid and $0.01 \mathrm{~mol} / \mathrm{l} \mathrm{NaBH}_{4}$, solution II was composed of $0.2 \mathrm{~mol} / /$ cetyltrimethyl ammonium bromide, $4 \times 10^{-3} \mathrm{~mol} / \mathrm{l}$ silver nitrate, $1 \times 10^{-3} \mathrm{~mol} / \mathrm{l}$ chloroauric acid and $0.08 \mathrm{~mol} / \mathrm{l}$ ascorbic acid. (B) GNRs were purified by centrifugation at $1 \times 10^{4} \mathrm{r} / \mathrm{min}$ for $10 \mathrm{~min}$ at $28^{\circ} \mathrm{C}$. DDW was used for resuspension of the purified GNRs.

DDW: Double distilled water; GNR: Gold nanorod.

typical cell culture incubation, serum proteins are first absorbed onto the surfaces of GNRs. Then, RME occurs through interactions between ligands on the GNR surface and receptors located on the cell membrane, such as clathrin and caveolin $[24,25]$. Then, these internalized GNRs are relocalized in endosomes and finally fuse with lysosomes for degradation and recycling [22].

Lysosomes are the key intracytoplasmic organelle affecting GNR function. The lysosome is characterized by an acidic milieu (i.e., a $\mathrm{pH}$ of approximately 4.5-5.0) and a single cytoplasmic membrane that contains various hydrolytic enzymes, including proteases, lipases and nucleases. These enzymes play an important role in exerting the activity of lysosomes [26]. Notably, lysosomes are different in normal versus cancer cells. The normal lysosomal membrane is stable to prevent lysosomal degradation of intracellular organelles, thus keeping the intracellular environment in an orderly and balanced state. By contrast, lysosomal membranes in cancer cells are relatively vulnerable. When the lysosome is destroyed, substantial hydrolases or drug molecules are released and may be translocated to other organelles, such as the mitochondria. The subsequent mitochondrial membrane is damaged, leading to the release of a large amount of cytochrome C, reactive oxygen species and other substances. Some of these released factors are involved in the downstream cellular outcomes, including apoptosis [27,28].

Thus, an in-depth understanding of the intracellular fate and route of GNRs when they interact with intracellular organelles is necessary for promoting their clinical application. Importantly, knowledge of the interaction between GNRs and lysosomes, the mitochondrial state and subsequent effectors is required to determine the intracellular mechanisms employed by GNRs. Previously, we developed a nanobased multifunctional antibody with weak positive charges that induced lymphoma cells that were susceptible to apoptosis. Such apoptosis was characterized by the aforementioned lysosomal membrane permeabilization (LMP) and mitochondrial depolarization [29]. In this case, vast amounts of lysosomal enzymes are released into the cytosol due to LMP. These proteases cause a decrease in the mitochondrial membrane potential, resulting in the release of cytochrome $\mathrm{C}$ and caspase- 3 and caspase-9 activation [30] . Other studies have used fluorescent images to track the intracellular path of nanoparticulates [31]. However, few works have determined the effectors that are induced and whether apoptosis is evoked in cancer cells when they interact with GNRs.

Recently, we prepared GNRs via a seeded growth method. As synthesized, the GNRs are able to kill cancer cells while posing little influence on normal cells, and determining why the GNRs specifically killed the cancer cells is of interest. In this work, the intracellular fate and the detailed working mechanism of GNRs were systematically investigated using laser light scattering, transmission electron microscopy (TEM), flow cytometry, confocal microscopy and western blot analyzes. 


\section{Materials \& methods}

Main chemicals \& apparatus

Cetyltrimethyl ammonium bromide (CTAB) was purchased from Sinopharm Chemical Reagent Co., Ltd (Shanghai, China). Chloroauric acid $\left(\mathrm{HAuCl}_{4}\right)$, sodium borohydrid $\left(\mathrm{H}_{4} \mathrm{BNa}\right)$, silver nitrate $\left(\mathrm{AgNO}_{3}\right)$ and ascorbic acid were purchased from Sigma-Aldrich Co. (MO, USA). A mitochondrial membrane potential assay kit with JC-1 was purchased from Beyotime Biotechnology Co., Ltd (Jiangsu, China). An Annexin V-FITC/PI Apoptosis Detection Kit was purchased from Becton, Dickinson and Co. (NJ, USA). Rabbit anti-caspase-3 and rabbit anti-caspase-9 antibodies were both purchased from the American Cell Signaling Technology Company (MA, USA). The apparatus mainly included a UV-VIS spectrophotometer (Cary300, Varian, CA, USA), a Zetasizer Nano ZSP (Malvern Instruments, UK), an infrared system (IRS-S6, Shanghai, China),

(A)

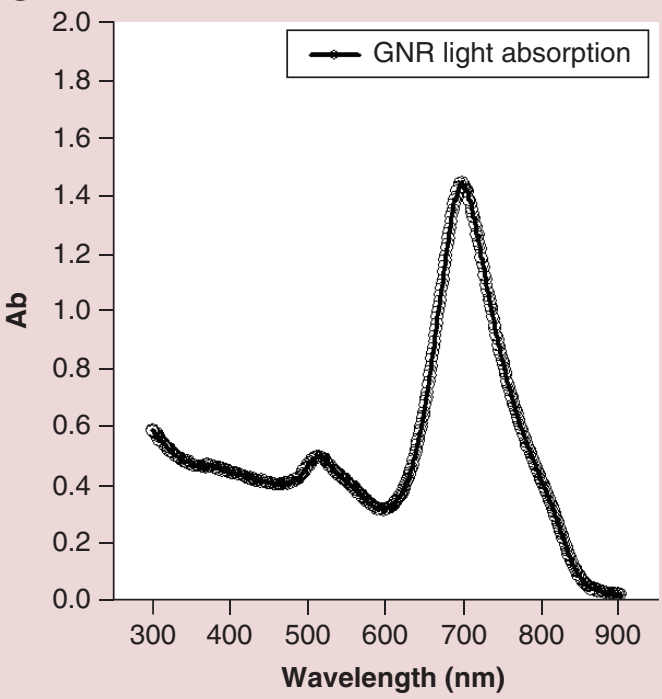

(C)

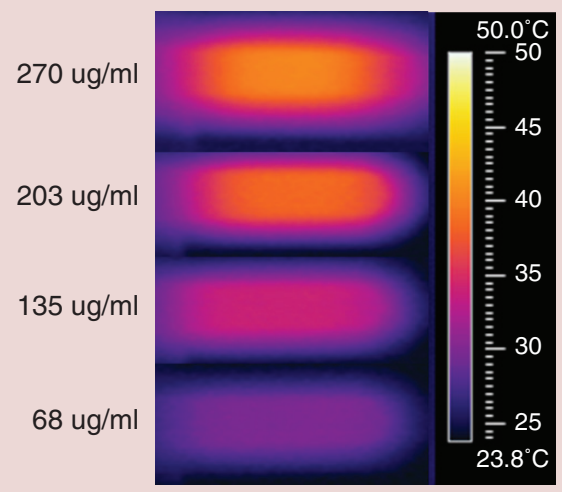

a TEM (Hitachi, H-7000 Electron Microscope, Tokyo, Japan), a flow cytometer (FACSCalibur; Becton Dickinson, CA, USA), a confocal laser scanning microscope (CLSM, Zeiss LSM 710; Carl Zeiss Meditec AG, Jena, Germany) and a Bio-RAD gel imaging system (ChemiDoc XRS, USA).

\section{GNR synthesis}

For the preparation of the gold seed solution, $5 \mathrm{ml}$ of $0.2 \mathrm{~mol} / \mathrm{l}$ CTAB was kept in a clean glass bottle under vigorous stirring in a $28^{\circ} \mathrm{C}$ water bath; then, $5 \mathrm{ml}$ of $5 \times 10^{-4} \mathrm{~mol} / \mathrm{l}$ gold salt $\left(\mathrm{HAuCl}_{4}\right)$ solution was added dropwise, followed by adding $600 \mu \mathrm{l}$ of $0.01 \mathrm{~mol} / \mathrm{l}$ $\mathrm{NaBH}_{4}$ slowly [32]. As a result, the light yellow solution gradually turned tawny, and the solution was stirred for another $2 \mathrm{~h}$ for seed formation.

GNRs were synthesized according to the following steps: $25 \mathrm{ml}$ of $0.2 \mathrm{~mol} / \mathrm{l} \mathrm{CTAB}$ was placed into a $50-\mathrm{ml}$

\section{(B)}

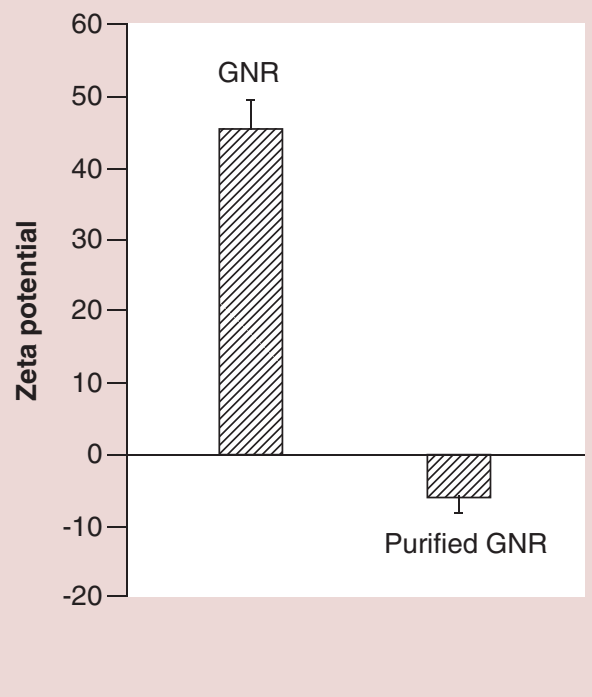

(D)

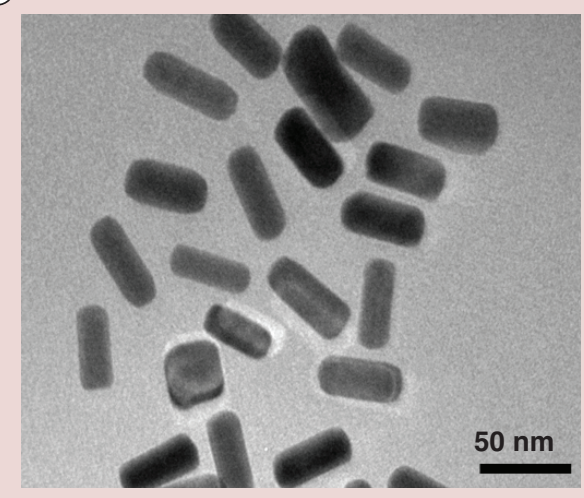

Figure 2. Gold nanorods physicochemical characteristics. (A) Optical absorption curve of the GNRs. (B) The zeta potential of GNRs before and after purification. (C) Photothermal transduction efficiency at different concentrations of GNRs. (D) Transmission electron microscopy image of GNRs.

Ab: Absorbance; GNR: Gold nanorod. 
(A)

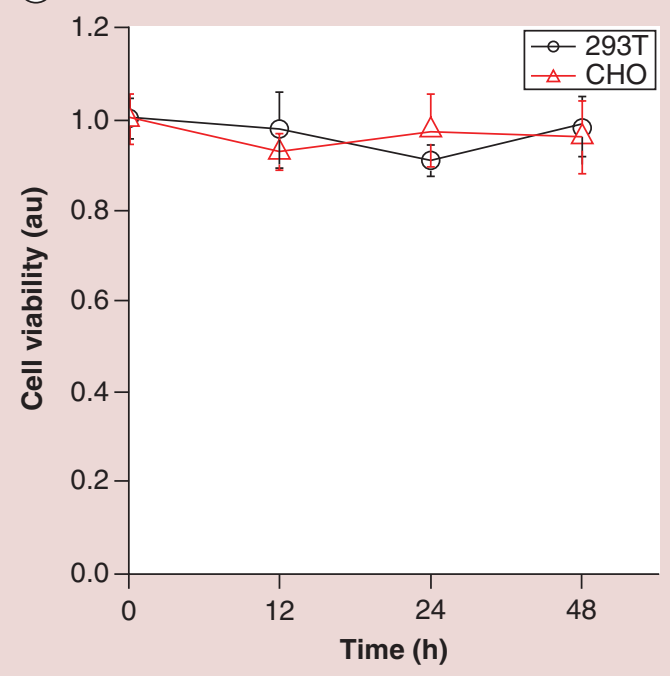

(B)

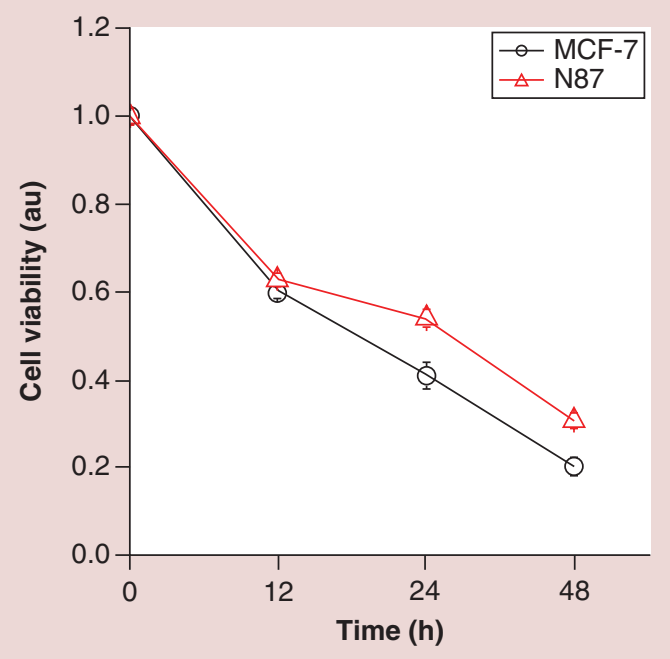

Figure 3. Cell viability after incubation with gold nanorods for different periods of time $(0,12,24$ and $48 \mathrm{~h})$. (A) Viability of 293T and CHO cells. (B) Viability of MCF-7 and N87 cells. Data are expressed as mean \pm standard deviation $(n=3)$.

$\mathrm{CHO}$ : Chinese hamster ovary.

chloroazotic acid-soaked beaker and maintained with slow stirring in a $28^{\circ} \mathrm{C}$ water bath; $750 \mu \mathrm{l}$ of $4 \times 10^{-3}$ $\mathrm{mol} / \mathrm{l} \mathrm{AgNO}_{3}$ was added. Next, $25 \mathrm{ml}$ of $1 \times 10^{-3} \mathrm{~mol} / \mathrm{l}$ $\mathrm{HAuCl}_{4}$ was slowly added, and the solution turned golden yellow as the reaction proceeded. Then, $350 \mu \mathrm{l}$ of $8 \times 10^{-2} \mathrm{~mol} / \mathrm{l}$ ascorbic acid was slowly added, and the solution color disappeared due to the reduction of $\mathrm{Au}^{2+}$ to $\mathrm{Au}^{+}$. Finally, $60 \mu \mathrm{l}$ of the above-prepared gold seed solution was added, and the clear solution turned back to dark brown; after stirring for another $2 \mathrm{~h}$, GNRs were obtained. Because the aqueous solubility of CTAB is susceptible to the ambient environment, the stock solution of GNRs was purified by centrifugation at a speed of $1 \times 10^{4} \mathrm{r} / \mathrm{min}$ for $10 \mathrm{~min}$ under a constant temperature of $28^{\circ} \mathrm{C}$. Then, the supernatant was discarded, and the precipitate was resuspended in double-distilled water.

\section{Characterization of GNRs}

The light absorption profile of the GNRs was detected using a UV-VIS spectrophotometer. After the GNRs were dispersed in deionized water, their zeta potential was analyzed using a Zetasizer Nano ZSP. The photothermal transduction efficiency was identified using an infrared system. TEM was used to characterize the morphology of the GNRs. Conventional TEM images were obtained at $200 \mathrm{kV}$ with a magnification of 80,000 times.

\section{Cytotoxicity assays}

Chinese hamster ovary (CHO), 293T (human renal epithelial), MCF-7 (breast cancer) and N87 (gastric cancer) cells were cultured in Roswell Park Memorial Institute medium (RPMI) 1640 medium and supplied with $10 \%$ fetal bovine serum, $50 \mathrm{unit} / \mathrm{ml}$ penicillin and $50 \mathrm{mg} / \mathrm{ml}$ streptomycin in a humidified $37^{\circ} \mathrm{C}$ environment with $5 \% \mathrm{CO}_{2}$. Prior to the cellular experiments, CHO, 293T, MCF-7 and N87 cells were seeded into 96-well microplates $\left(0.1 \mathrm{ml} /\right.$ well, $5 \times 10^{3}$ cells/well $)$ and cultured overnight until the cells reached $80 \%$ confluence. Then, the cells were incubated with GNRs at $37^{\circ} \mathrm{C}$ for $12,24,36$ and $48 \mathrm{~h}$. A Cell Counting Kit-8 (Dojindo Laboratories, Kumamoto, Japan) assay was performed according to the manufacturer's protocol to measure cell viability after GNR treatment. After incubation for $1.5 \mathrm{~h}$, the absorption of the samples in each well was measured using a BIO-TEK ELx800 Universal Microplate Reader (Bio-Tek, VT, USA) at wavelengths of 450 and $630 \mathrm{~nm}$. The cell survival rate was calculated with the following formula: $\left[\left(A_{E}-A_{B}\right) /\left(A_{C}-A_{B}\right)\right] \times 100 \%$, where $A_{E}, A_{C}$ and $A_{B}$ represent the absorbance of the experimental cells, control cells and background, respectively.

\section{Apoptotic cells evaluated by flow cytometry}

The in vitro apoptosis induced by GNRs was analyzed as described below [33]. Briefly, MCF-7 cells were seeded into 24-well plates $\left(1 \times 10^{4}\right.$ cells/well $)$ and incubated overnight. After the cells reached $80 \%$ confluence, they were treated with GNRs at $37^{\circ} \mathrm{C}$ for $12,24,36$ and $48 \mathrm{~h}$. The cells were trypsinized, collected, washed and finally suspended in one-time binding buffer, followed by staining with an Annexin-V antibody labeled 
with Alexa Fluor- 488 for $15 \mathrm{~min}$ at room temperature in the dark and propidium iodide (PI) for $2 \mathrm{~min}$ in the dark. Then, the apoptotic cells were analyzed by twochannel flow cytometry, assaying FL-1 (Annexin-V) and FL-2 (PI) with excitation at $488 \mathrm{~nm}$ and emission at $520 \mathrm{~nm}$.

\section{Mitochondrial membrane potential changes observed by CLSM}

The mitochondrion-specific dye JC-1 was used to detect changes in the mitochondrial membrane potential of $\mathrm{CHO}$ and MCF-7 cells after differ- ent exposure times to GNRs. First, the $\mathrm{CHO}$ and MCF-7 cells were precultured in laser scanning confocal dishes at a density of $2 \times 10^{5}$ cells per well overnight. Then, cells in the experimental groups were treated with GNRs for different time periods (12, 24 and $48 \mathrm{~h}$ ) at $37^{\circ} \mathrm{C}$. Untreated cells were used as control. JC-1 working solution was prepared according to the manufacturer's protocols. After washing with phosphate-buffered saline (PBS), the cells were stained with $\mathrm{JC}-1$ for $20 \mathrm{~min}$ at $37^{\circ} \mathrm{C}$. Then, the samples were rinsed with JC-1 staining buffer twice and resuspended in culture medium in the presence
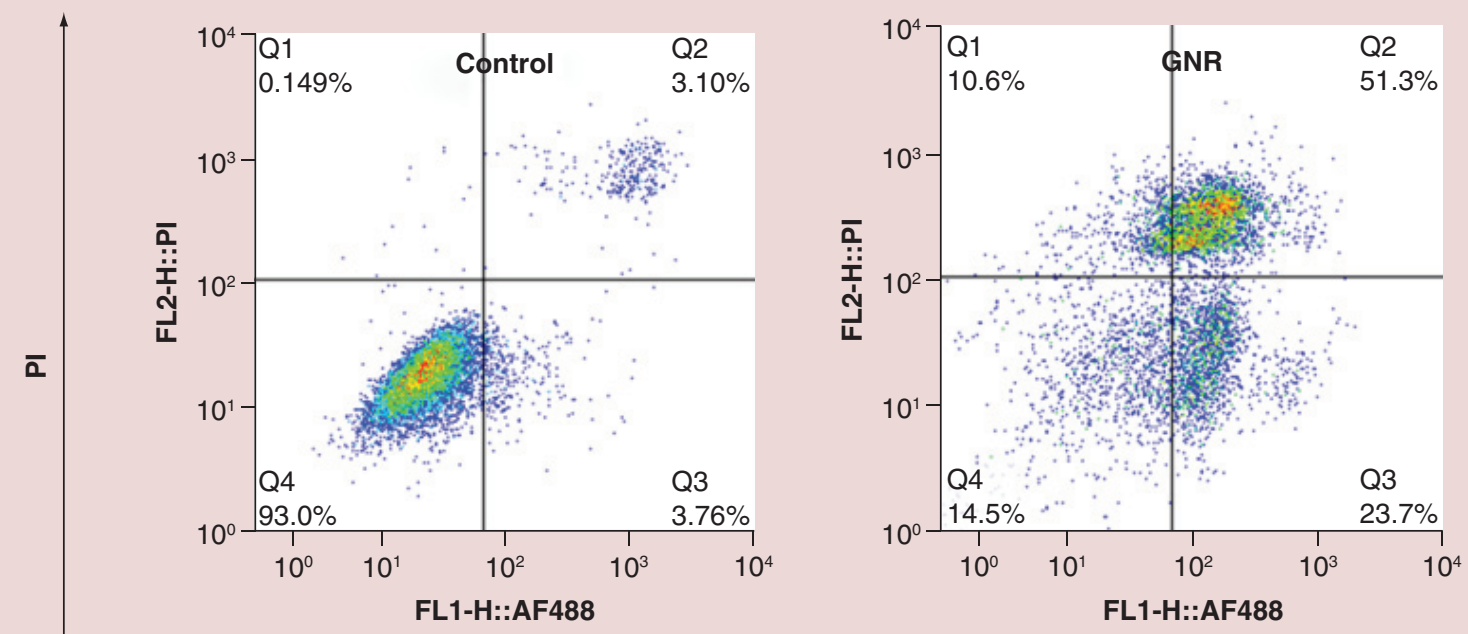

Annexin V

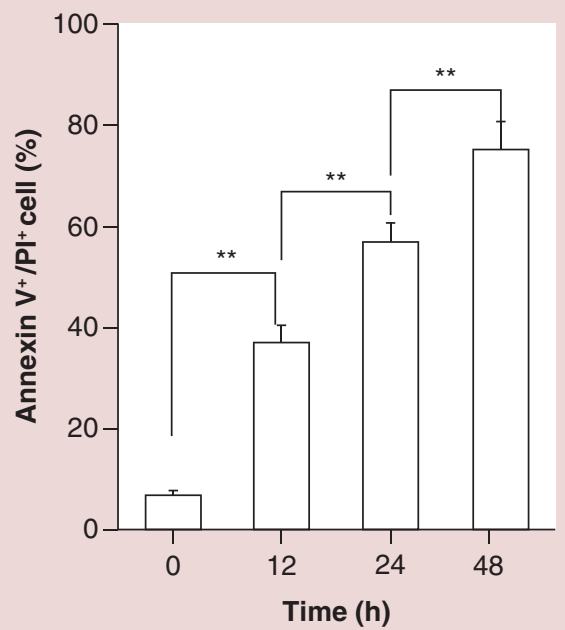

Figure 4. Flow cytometric analysis of apoptotic MCF-7 cells. (A) The distribution of apoptotic MCF-7 cells after incubation with GNRs for $0 \mathrm{~h}$ and $48 \mathrm{~h}$. (B) The proportion of apoptotic MCF-7 cells after incubation with GNRs for different periods of time $(0,12,24$ and $48 \mathrm{~h})$.

GNR: Gold nanorod; PI: Propidium iodide. 


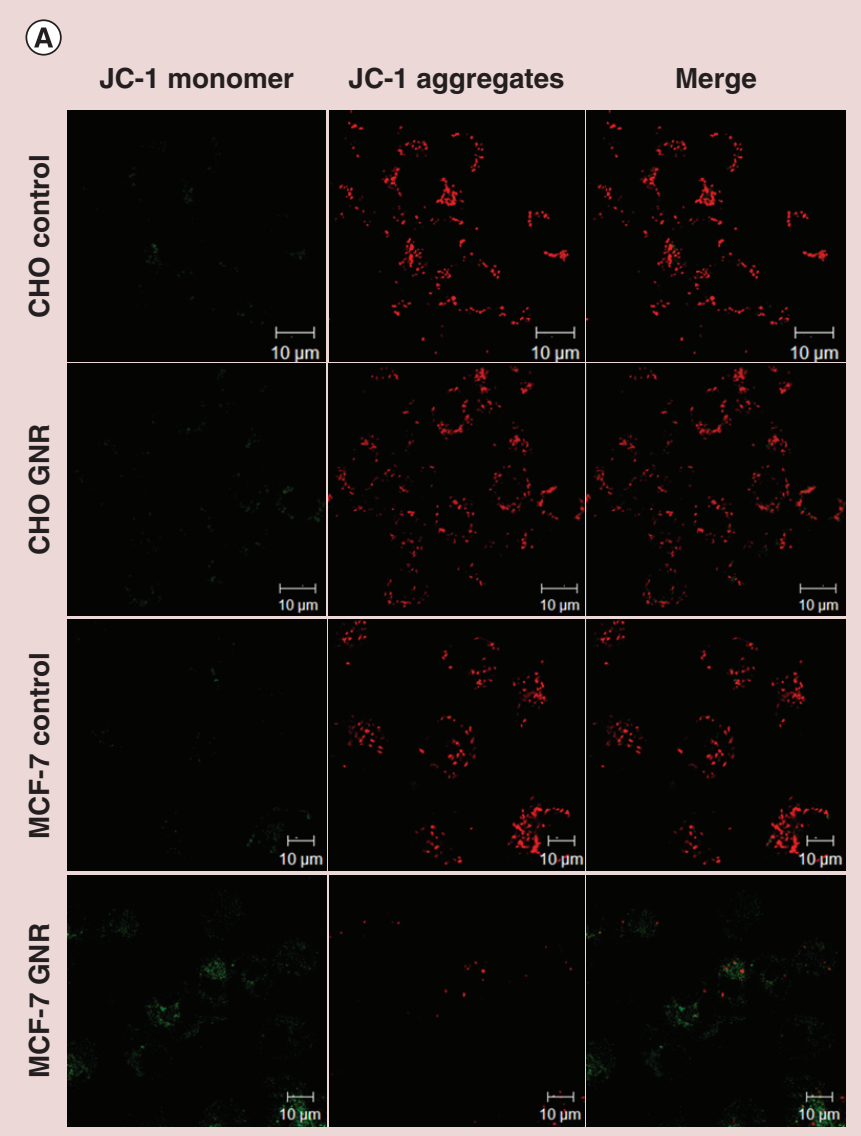

(B)

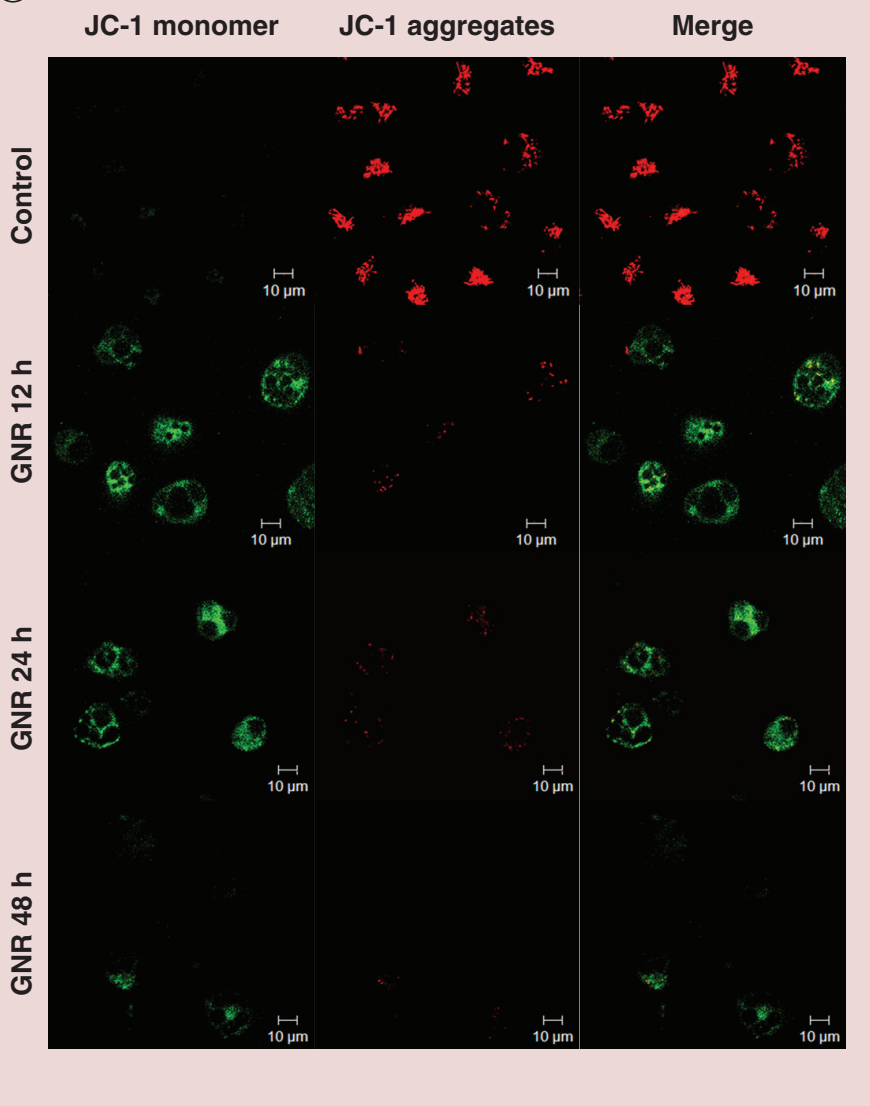

Figure 5. Confocol microscopic images reflecting the mitochondrial membrane potential changes. (A) Differences in mitochondrial membrane potential between CHO and MCF-7 cells. (B) The mitochondrial membrane potential changes of MCF-7 cells at different exposure times to GNRs.

CHO: Chinese hamster ovary; GNR: Gold nanorod.

or the absence of fetal bovine serum or phenolsulfonphthalein. Finally, the samples were observed with a confocal microscope.

\section{Lysosomal changes of normal cells \& cancer cells}

$\mathrm{CHO}$ and MCF-7 cells were seeded onto poly-D-lysinecoated microscope slides and incubated overnight at $37^{\circ} \mathrm{C}$. Cells were treated with GNR for $24 \mathrm{~h}$. Then, the samples were fixed for $10 \mathrm{~min}$ with a precooled fixation liquid (methanol/acetone $=7 / 3$ ), washed three-times with precooled PBS and incubated for $1 \mathrm{~h}$ with $1 \mathrm{ml}$ of sealing liquid (1\% fetal calf serum [FCS] $)$ at room temperature. Rabbit anti-LAMP-2 (primary antibody) and donkey anti-rabbit-AF488 (secondary antibody) were used to detect LAMP-2, a lysosomal membrane-associated protein, to determine the location, shape and size of the lysosomes. Mouse anti-cathepsin D (primary antibody) and rabbit antimouse-AF555 (secondary antibody) were used to detect intracellular cathepsin $\mathrm{D}$. Then, the cells were incubated with $1 \mathrm{ml}$ of the primary antibody at $4^{\circ} \mathrm{C}$ overnight, washed three-times with precooled PBS and incubated with $1 \mathrm{ml}$ of the secondary antibody for $2 \mathrm{~h}$ at room temperature. Finally, the cells were visualized by confocal microscopy [29]. By analyzing the above results, changes in lysosomal permeabilization, that is, cathepsin $\mathrm{D}$ dissemination degree around the lysosomes, were obtained.

\section{Intracellular distribution of GNRs detected by TEM}

To follow detailed trafficking of GNRs after their internalization into cells, MCF-7 cells were treated with GNRs for $24 \mathrm{~h}$ at $37^{\circ} \mathrm{C}$. Then, the cells were rinsed with $\mathrm{PBS}$, fixed with precooled $4 \%$ paraformaldehyde, scraped with a cell scraper, collected by centrifugation, embedded in epoxy resin and sliced with a microtome. TEM images were obtained at $200 \mathrm{kV}$ [34]. The intracellular distribution of GNRs and mitochondrial changes in MCF-7 cells were observed. 


\section{Western blot}

MCF-7 cells were treated with GNRs for 12, 24 and $48 \mathrm{~h}$. Equal amounts of extracted proteins were separated by $10 \%$ SDS-polyacrylamide gel electrophoresis and transferred onto polyvinylidenedifluoride membranes (Millipore, MA, USA). For immunoblotting, membranes were blocked with $5 \%$ bovine serum albumin for $1 \mathrm{~h}$ at room temperature, rabbit anti-caspase-3/9 antibody (1:1000 dilution) at $4^{\circ} \mathrm{C}$ overnight and horseradish peroxidase-conjugated goat anti-rabbit $\operatorname{IgG}(1: 2000$ dilution) for $1 \mathrm{~h}$ at room temperature. The immuno reactive bands were detected by enhanced chemiluminescence (Amersham, UK), visualized using a Bio-Rad ChemiDoc XRS system and analyzed with Quantity One Version 4.6.2 software.

\section{Statistical analysis}

Statistical analysis was performed by student's T-test or one-way analysis of variance to identify significant differences unless otherwise mentioned. Differences were considered significant at a $\mathrm{p}$-value of $<0.05$, whereas $\mathrm{p}>0.05$ represents not significant.

\section{Results}

\section{Characterization of GNRs}

The GNRs were prepared using the gold seed-mediated growth method, and the overall synthesis process of GNRs is shown in Figure 1. We first synthesized gold seeds with $\mathrm{CTAB}, \mathrm{HAuCl}_{4}$ and $\mathrm{H}_{4} \mathrm{BNa}$ (solution I). Then, the gold seeds were placed into solution II, and GNRs were obtained by stirring. Solution II was a mixed solution of CTAB, $\mathrm{AgNO}_{3}, \mathrm{HAuCl}_{4}$ and ascorbic acid. The purified GNRs were obtained by centrifugation at $1 \times 10^{4} \mathrm{r} / \mathrm{min}$ for $10 \mathrm{~min}$. Then, the supernatant was discarded, followed by resuspension of the precipitate with double-distilled water. The centrifugation and resuspension processes were repeated three-times. Finally, we tested the physicochemical properties of the GNRs (Figure 2). First, the light absorption profile of the GNRs was detected using a UV-vis spectrophotometer; the result revealed that GNRs had two absorption peaks at 520 and $690 \mathrm{~nm}$ (Figure 2A). Then, the surface potential of the GNRs was detected using a Zetasizer Nano ZSP. The original GNR solution presented a strong positive charge, whereas its charge turned weak and negative after purification (Figure 2B). CTAB, a surfactant molecule, adsorbed onto the surface of rod-shaped NPs during synthesis. With the removal of the cationic saponification molecules from the surfaces of GNRs after purification, the surface potential rapidly decreased. The GNRs' photothermal transduction characteristics were detected with different GNR concentrations $(68,135$, 203 and $270 \mu \mathrm{g} / \mathrm{ml}$ ) using an infrared system. The analysis showed that a temperature increase positively correlated with GNR concentration; thus, GNRs might have a potential application as a photothermal therapy reagent (Figure 2C). A typical TEM image of the synthesized GNRs with clear, rod-like structures, is shown in Figure 2D. The long diameters of the GNRs ranged from 50 to $60 \mathrm{~nm}$, and the short diameters ranged from 20 to $30 \mathrm{~nm}$.

\section{GNRs enhance cytotoxicity against cancer cells}

The cytotoxic effect of GNRs was evaluated in the normal cell lines $\mathrm{CHO}$ and 293T and in the cancer cell lines MCF-7 and N87. The cells were exposed to GNRs for different times. As shown in Figure 3A, the survival rates of $293 \mathrm{~T}$ and $\mathrm{CHO}$ cells were constant as the incubation time increased, indicating that GNRs were nontoxic to normal cells. However, the survival rates of MCF-7 and N87 cells decreased significantly from 100 to $20 \%$ after $48 \mathrm{~h}$ of GNR treatment (Figure 3B), indicating that GNRs exhibited robust toxic effects on cancer cells. The cytotoxicity assay indicated that GNRs inhibited the proliferation of cancer cells while possessing negligible toxicity to normal cells.

\section{GNRs enhance apoptosis against cancer cells}

The in vitro apoptosis-inducing capacity of GNRs was evaluated via flow cytometry using $1 \times 10^{4}$ MCF-7 cells for each sample. The samples were incubated with GNRs for different periods of time under the same conditions. After staining, apoptotic cells were characterized based on Annexin $\mathrm{V}^{+}$subsets, and they were positioned at the Q2 and Q3 zones. As shown in Figure 4A, in comparison with the control group, after treatment with GNRs for 12, 24 and $48 \mathrm{~h}$, the proportions of apoptotic cells sharply increased from 6.86 to $37.46,56.8$ and $75.0 \%$, respectively. The proportion of apoptotic cells induced by GNRs increased in a time-

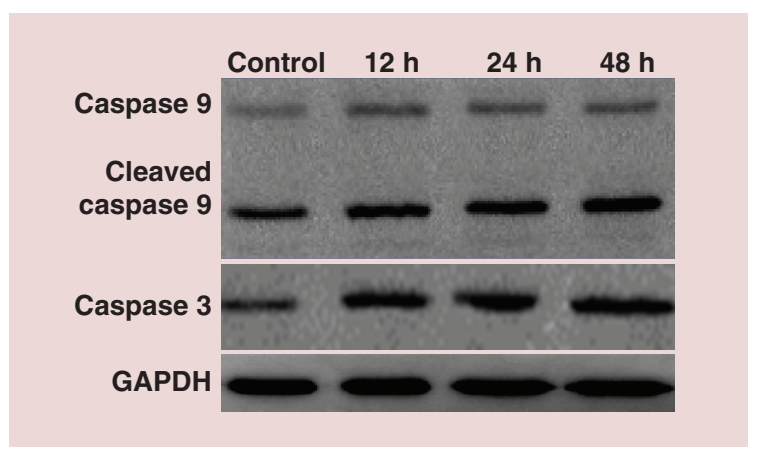

Figure 6. Proteins were extracted from MCF-7 cells at different time intervals after treatment with gold nanorods, and were subjected to immunoblot analysis for the detection of caspase-3 and caspase-9 expression. Equal loading was confirmed by stripping the blot and reprobing it for GAPDH. 


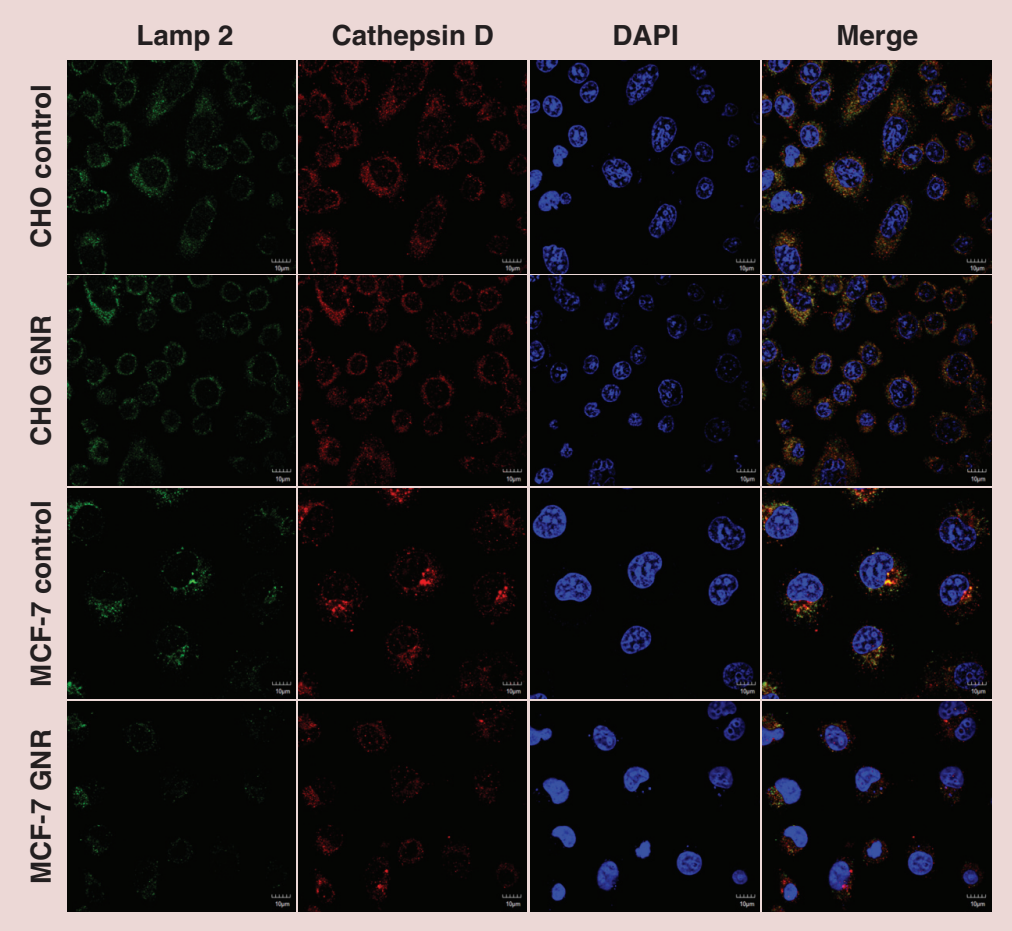

Figure 7. The integrity of lysosomal membrane and dissemination of cathepsin D in Chinese hamster ovary cells and MCF-7 cells.

CHO: Chinese hamster ovary; DAPI: 4,6-diamidino-2-phenylindole; GNR: Gold nanorod.

dependent manner (Figure 4B). The flow cytometry results fully demonstrated that GNRs have a potent capacity to induce apoptosis.

\section{Mitochondrial membrane potential changes}

To determine the relationship between mitochondria and the cell apoptosis induced by GNRs, the mitochondrionspecific dye JC-1 was used to detect changes in the mitochondrial membrane potential. The mitochondrial membrane potential of healthy cells is relatively high and shows red fluorescence, while the mitochondrial membrane potential of apoptotic cells is decreased and shows green fluorescence, making JC-1 suitable for the detection of mitochondrial damage [35,36].

The JC-1 results showed that GNRs-induced mitochondrial damage in MCF-7 cells but not in $\mathrm{CHO}$ cells. The red and green fluorescence levels of $\mathrm{CHO}$ cells seldom changed in the presence or absence of GNRs, implying that the mitochondrial membranes were intact after incubation with GNRs in normal cells. By contrast, MCF-7 cells showed an increased ratio of green to red fluorescence after interaction with GNRs, which was the result of impaired mitochondrial membranes in cancer cells (Figure 5A).

To further explain the correlation between cell apoptosis and mitochondrial damage, changes in the mitochondrial membrane potential of MCF-7 cells were detected at different time intervals. As revealed in Figure $5 \mathrm{~B}$, the ratio of green to red fluorescence increased after 12 or $24 \mathrm{~h}$ of treatment with GNRs, indicating that the mitochondria in MCF-7 cells were seriously damaged. Cells exhibiting signs of mitochondrial depolarization were undergoing early apoptosis. However, after $48 \mathrm{~h}$ of treatment with GNRs, the green fluorescence diminished. This finding might be the result of a complete mitochondrial membrane disruption with continuous exposure to GNRs. Therefore, mitochondrial damage was involved in the cancer cell apoptosis induced by GNRs.

\section{Overexpression \& activation of caspases in MCF-7 cells}

To verify our hypothesis that mitochondria play a key role in the apoptosis process induced by GNRs, cleaved caspase- 9 , caspase- 9 and caspase- 3 proteins in MCF-7 cells were detected by western blot. Cleaved caspase-9 is an activated form of caspase- 9 that is involved in mitochondria-related apoptosis. Caspase-9 is a key molecule that activates caspase- 3 and initiates apoptosis [27]. The western blotting results revealed that caspase- 9 was persistently activated as the incubation time with GNRs increased. Then, caspase-9 triggered caspase-3 activation [42]. Thus, caspase-9, cleaved caspase- 9 and caspase- 3 proteins were upregulated and 
increasingly expressed in GNR-treated MCF-7 cells compared with the control group (Figure 6). The above results clearly showed that GNR-induced cancer cell apoptosis proceeded in a caspase-dependent pathway.

Lysosome changes in normal cells \& cancer cells After internalization, GNRs were taken up by lysosomes. To reflect the influence of GNRs on lysosomes in MCF-7 and CHO cells, the lysosomal membrane and the lysosomal enzyme cathepsin $\mathrm{D}$ were detected by immunofluorescence. The lysosomal membrane is protected from acidic hydrolases by specific expression of lysosomal membrane proteins, such as LAMP-1 and LAMP-2. The proteins are heavily glycosylated and, hence, resist digestion. As reflected in Figure 7, compared with untreated $\mathrm{CHO}$ normal cells, the lysosomal membrane protein LAMP-2 and the lysosomal enzyme cathepsin D hardly changed in the GNR-treated counterparts. These results indicated that the lysosomes in $\mathrm{CHO}$ cells were not affected before or after exposure to GNRs. However, compared with untreated MCF-7 breast cancer cells, green and red fluorescence intensities were reduced in GNR-treated cells. This result indicated that the lysosomes in MCF-7 cells were evidently damaged after incubation with GNRs. Moreover, dissemination of cathepsinD was detected within the GNR-treated MCF-7 cells due to lysosomal damage. As a major intracellular aspartic protease, cathep$\sin \mathrm{D}$ plays a role in determining the initiation of apoptosis. The release of cathepsin $\mathrm{D}$ from lysosomes to the cytosol precedes the release of cytochrome $\mathrm{C}$ and the decrease in the mitochondrial membrane potential [37]. The results reflected that the lysosomes in $\mathrm{CHO}$ cells remained intact and that the integrity of the mitochondria was not affected. By contrast, the lysosomes in MCF-7 cells were severely disrupted and further damaged the mitochondrial membranes. Mitochondrial damage further activated the apoptosis-associated signaling pathways.

\section{Intracellular GNR distribution \& mitochondrial changes}

As a 'gold standard', TEM provides spatial and temporal information about the endocytosis and intracellular path of GNRs. The TEM images showed many normal mitochondria $(\mathrm{M})$ and few lysosomes $(\mathrm{L})$ in the control group, while damaged mitochondria (M) were found in the GNR-12H, GNR-24H and GNR$48 \mathrm{H}$ groups. The lysosomes $(\mathrm{L})$ were impaired in the GNR-12H group, and autolysosomes (L) were caught in the GNR-24H and GNR-48H groups. Moreover, few nanorods were detected in most of the damaged mitochondria but were found in lysosomes (Figure 8). Such selective accumulation of the GNRs in lysosomes indicated that the GNRs were not directly involved in the mitochondrial damage. The damage might occur through protease release from lysosomes, such as cathepsin $\mathrm{D}$, to trigger the mitochondria-mediated caspase apoptotic pathway. Furthermore, the lamellar cristae of mitochondria became irregular and disordered, and the mitochondrial structures became vacuolous, implying that the lysosomal aggregation of GNRs resulted in mitochondrial damage. Consistent with other reports, GNRs were not detected in the nucleus, thus eliminating the possibility of genotoxicity. As expected, the number of internalized GNRs was time-dependent; more GNRs entered the cells if the incubation time increased.

\section{Discussion}

In this work, GNRs with rod-like structures and unique physicochemical properties were successfully prepared using the gold seed-mediated growth method. Interestingly, the cytotoxicities against tumor cells and normal cells were very different. GNRs selectively kill cancer cells while having little impact on normal cells. This result may be due to intrinsic differences between cancer cells and normal cells, such as oncogenic activation, the epithelial-mesenchymal transition, cell surface molecule expression, structural differences in the lysosomal membrane, among others [26,38-40]. By cytometric analysis, we discovered that the proportion of apoptotic cells increased with increasing incubation time. Apoptosis is frequently viewed as a result of explosive activation of the caspase cascade [41]. Caspases are aspartic proteases that are responsible for the degradation of hundreds of cytoplasmic and nuclear

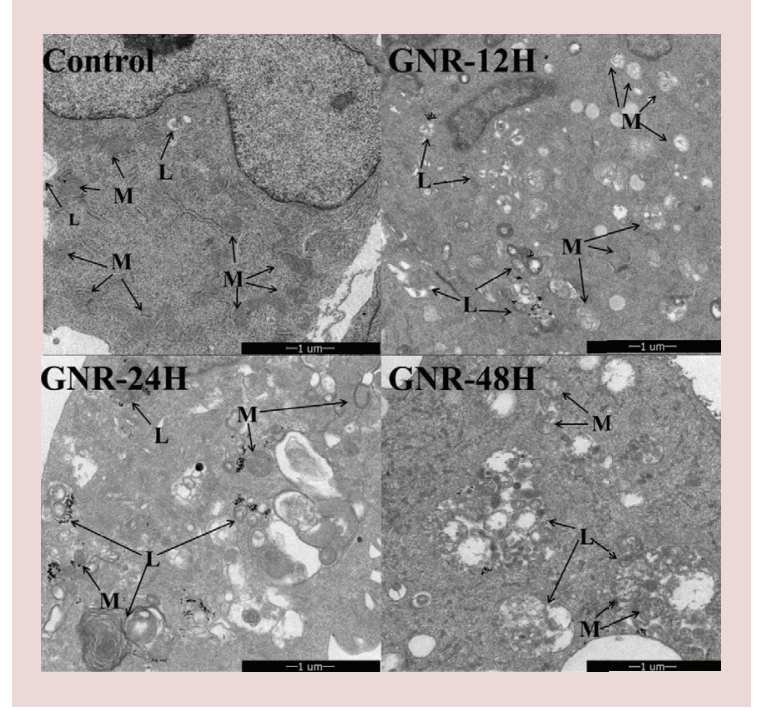

Figure 8. Mitochondrial changes and distribution of gold nanorods in MCF-7cells were observed by transmission electron microscopy. GNR: Gold nanorod. 


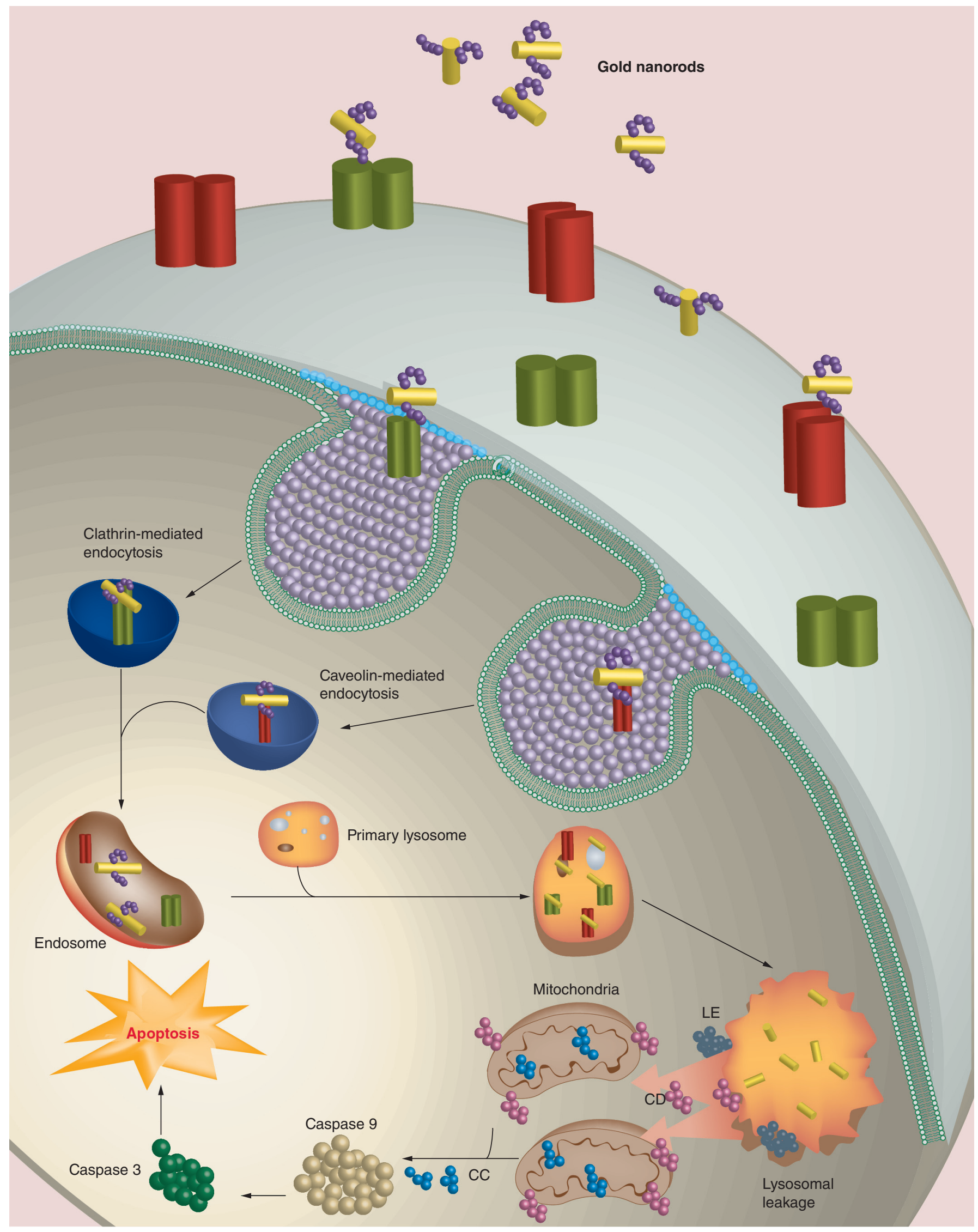


Figure 9. The gold nanorod-induced apoptosis in lysosomal-mitochondrial-related mechanism. CC: Cytochrome C; CD: Cathepsin D; LE: Lysosomal enzyme.

proteins in apoptotic cells. Caspases can be activated by cathepsins $\mathrm{D} / \mathrm{B}$, cytochrome $\mathrm{C}$ and mitochondrial outer membrane permeabilization (MOMP) [42,43]. As mentioned above, subcellular components, such as lysosomes and mitochondria, play crucial roles in apoptosis [44]. However, the identification of the corresponding effectors induced by the intracellular interactions between GNRs and these subcellular components remains an unclear field.

A decrease in the mitochondrial membrane potential is a landmark event in the early stage of apoptosis. The transformation of JC-1 from red to green fluorescence can be regarded as a sign of early apoptotic cells with decreased in cell membrane potential [35]. As shown in Figure 5, the mitochondrial membrane potential of normal cells seldom changed in the presence or the absence of GNRs. On the contrary, the mitochondrial membrane potential of MCF-7 cells changed dynamically at different time intervals. After $12 \mathrm{~h}$ of treatment with GNRs, the mitochondrial membrane was depolarized so that the ratio of green to red fluorescence increased. Moreover, the mitochondria were seriously damaged; the lamellar cristae of mitochondria became irregular and disordered and the structures became vacuolus [45]. When the interaction time was increased to $48 \mathrm{~h}$, the severely damaged mitochondria could not be restored. At the same time, after GNR treatment, the overexpression of caspase-9 in GNR-treated MCF-7 cells activated caspase-9, which subsequently triggered caspase-3 activation. These findings strongly indicated that GNRinduced cancer cell death has a close relationship with mitochondrial destruction [46].

Figure 9 shows the detailed route of GNRs after cellular internalization and illustrated how the GNRs cause damage to the mitochondrial membrane. It is known that nanoparticulate formulations enter into cells mainly through receptor-mediated endocytosis resulted in the endosome. In the case of GNRs, the internalization firstly appeared in the endocytotic vesicle. After the clathrin coating was disassembled, the vesicle presented as an endosomal structure. So, post-RME, the GNRs reached the lysosomes following lysosome maturation in a spatial and temporal order, that is, the first step being the early endosome, gradually maturing into a late endosme and eventually a lysosome [26]. The results are shown in Figure 7. The lysosomes in $\mathrm{CHO}$ cells remained intact in the presence or the absence of GNRs, whereas the lysosomes in MCF-7 cells were obviously damaged. In addition, LMP led to the release of associated proteins, including cathepsin D, into the cytoplasm. Cathepsin D dissemination was detected in the cytosol of MCF-7 cells $[26,47]$. Cathepsin $\mathrm{D}$ was then translocated to the mitochondria, where it bored pores in the outer mitochondrial membrane so that the integrity of the mitochondrial membrane was destroyed $[37,44]$. Thus, mitochondrial dysfunction activated apoptotic signaling pathways. Interestingly, Figure 8 shows that the majority of GNRs endocytosed by MCF-7 cells were distributed in lysosomes, while few nanorods were detected in most of the damaged mitochondria [48]. This result indicated that the GNRs were not directly involved in mitochondrial damage. As shown in Figure 9, the released aspartate protease cathepsin D was liberated from the lysosomal lumen and translocated to the cytosol. Then, cathepsin D triggers Bax activation and relocation to mitochondria, resulting in the opening of the permeability transition pore and MOMP [37]. MOMP promotes the release of cytochrome C, followed by activation of apoptotic cascades [44]. We know that gold particles, such as cubic, triangular, rhombic and star-like NPs, can be prepared in experiments for catalysis, plasmonics, sensing and spectroscopy. The triangular shaped gold NPs are promising nanomaterials for applications in biosensing and bioimaging. GNRs are mainly applied in biomedicine such as near-infrared imaging, x-ray computed tomography, biosensing, gene-drug delivery and photothermal therapy. The properties of gold particles strongly depend on their shapes. The mechanism is very diverse and complex. Although it seems hard to clarify and compare the mechanism of all these particles in one work, it would be very interesting to study the potential apoptosis evoking ability of gold NPs with various shapes in the future.

\section{Conclusion}

In summary, GNRs were successfully synthesized using the seeded growth method. The results of in vitro experiments showed that GNRs were tremendously toxic to cancer cells but were nontoxic to normal cells. GNRs mainly induced apoptosis of cancer cells and the mechanisms behind the apoptosis were explored. Upon endocytosis, the intracellular GNRs damaged the lysosomal membrane, resulting in lysosomal permeabilization. Increased lysosomal membrane permeability led to lysosomal enzyme leakage, including cathepsin $\mathrm{D}$, which was translocated to the mitochondria, resulting in increased mitochondrial membrane permeability. Mitochondrial dysfunction quickly activated caspase-9, which further activated caspase- 3 , followed by an explosive activation of apoptotic cascades. Our study indicated that the 
disruption of lysosomes in GNR-treated cancer cells occurred before mitochondrial damage. Thus, the GNRs-induced cancer cell apoptosis by lysosomeand mitochondria-mediated routes with caspase-3/-9 activation.

\section{Future perspective}

GNRs are productive nanomaterials for potential biomedical applications such as near-infrared imaging, $\mathrm{x}$-ray computed tomography, photoacoustic imaging, biosensing, drug-gene delivery and thermal therapy of tumor, due to their unique physiochemical and optical properties. Physical properties of GNRs such as their charge, size, shape, aspect ratio and surface groups, can be finely tuned to tailor the intracellular processing of GNRs for effective uptake, removal and cytotoxicity against cancer cells. Our study represents an enormous advancement in the study of the molecular mechanisms and signaling pathways that mediate GNRs specifically induced cancer cell apoptosis. We anticipate our study will provide basis for better design of organelle-targeted nanomaterials in cancer therapy. GNRs have also been shown to be nontoxic to human healthy cells, hence, the clinical perspectives of gold nanostructure-based platforms are promising.
Financial \& competing interests disclosure

This work was financially supported by the National Natural Science Foundation of China including the project (31470964, 81400368), Ministry of Science and Technology of China (2012CB934002). The authors have no other relevant affiliations or financial involvement with any organization or entity with a financial interest in or financial conflict with the subject matter or materials discussed in the manuscript apart from those disclosed.

No writing assistance was utilized in the production of this manuscript.

Ethical conduct of research

The authors state that they have obtained appropriate institutional review board approval or have followed the principles outlined in the Declaration of Helsinki for all human or animal experimental investigations. In addition, for investigations involving human subjects, informed consent has been obtained from the participants involved.

\section{Open access}

This article is distributed under the terms of the Creative Commons Attribution License 4.0 which permits any use, distribution, and reproduction in any medium, provided the original author(s) and the source are credited. To view a copy of the license, visit http://creativecommons.org/licenses/by/4.0/

\section{Executive summary}

\section{Preparation \& characterization of gold nanorods}

- Gold nanorods (GNRs) with rod-like structures were successfully prepared by the seeded growth method. The surface charge, particle size and zeta potential could be finely tuned.

\section{Results \& discussion}

- GNRs exhibited intensive cytotoxicity against cancer cells while presenting slight impact on normal cells.

- The molecular mechanism concerning the intracellular fate of GNRs and the subsequent organelles changes. After cellular internalization, GNRs primarily accumulated in lysosomes and enhanced lysosomal membrane permeabilization.

- As reflected in our study, the destruction of lysosomes was prior to the mitochondria. Hence mitochondria were not directly damaged by GNRs, but by the proteases released from lysosomes, mainly cathepsin D.

- Mitochondrial dysfunction of cancer cells induced by GNRs activated caspases cascades and triggered the apoptotic pathway.

\section{Conclusion}

- GNR-induced cancer cell apoptosis is mediated by the lysosomal-mitochondrial pathway, which is a step forward in understanding the interactions between GNRs and cancer cells.

\section{References}

Papers of special note have been highlighted as:

- of interest; $\bullet$ of considerable interest

1 Li W, Zhao M, Ke C et al. Nano polymeric carrier fabrication technologies for advanced antitumor therapy. BioMed. Res. Int. 2013, 305089 (2013).

2 Li W, Feng S, Guo Y. Tailoring ofpolymeric micelles to optimize drug delivery to solid tumors. Nanomedicine (Lond.)7(8), 1235-1252 (2012).

3 Chen L, Chen F, Zhao M et al. A redox-sensitive micelle-like nanoparticle self-assembled from amphiphilic adriamycin- human serum albumin conjugates for tumor targeted therapy. BioMed. Res. Int. 2015, 987404 (2015).

4 Li H, Zhang G, Jiang C et al. Suppression of Rituximabresistant B-cell lymphoma with a novel multi-component anti-CD20 mAb nanocluster. Oncotarget 6(27), 24192-24204 (2015).

5 Gao J, Liu W, Xia Y et al. The promotion of siRNA delivery to breast cancer overexpressing epidermal growth factor receptor through anti-EGFR antibody conjugation by immunoliposomes. Biomaterials 32(13), 3459-3470 (2011). 
6 Daniel MC, Astruc D. Gold nanoparticles: assembly, supramolecular chemistry, quantum-size-related properties, and applications toward biology, catalysis, and nanotechnology. Chem. Rev. 104(1), 293-346 (2004).

- A good paper for introducing the nanogold.

7 Medintz IL, Uyeda HT, Goldman ER, Mattoussi H. Quantum dot bioconjugates for imaging, labelling and sensing. Nat. Mater. 4(6), 435-446 (2005).

8 De Volder MF, Tawfick SH, Baughman RH, Hart AJ. Carbon nanotubes: present and future commercial applications. Science 339 (6119), 535-539 (2013).

9 Wang Y, Ji L, Zhang B et al. Upconverting rare-earth nanoparticles with a paramagnetic lanthanide complex shell for upconversion fluorescent and magnetic resonance dualmodality imaging. Nanotechnology 24(17), 175101 (2013).

10 Li W, Guo Q, Zhao H et al. Novel dual-control poly(Nisopropylacrylamide-co-chlorophyllin) nanogels for improving drug release. Nanomedicine (Lond.) 7(3), 383-392 (2012).

11 Haley B, Frenkel E. Nanoparticles for drug delivery in cancer treatment. Urol. Oncol. 26(1), 57-64 (2008).

12 Xiong XB, Falamarzian A, Garg SM, Lavasanifar A. Engineering of amphiphilic block copolymers for polymeric micellar drug and gene delivery. J. Control Release 155(2), 248-261 (2011).

13 Jain PK, Lee KS, El-Sayed IH, El-Sayed MA. Calculated absorption and scattering properties of gold nanoparticles of different size, shape, and composition: applications in biological imaging and biomedicine. J. Phys. Chem. B 110 (14), 7238-7248 (2006).

14 Becker R, Liedberg B, Kall PO. CTAB promoted synthesis of Au nanorods - temperature effects and stability considerations. J. Colloid Interface Sci. 343(1), 25-30 (2010).

15 Yu C, Varghese L, Irudayaraj J. Surface modification of cetyltrimethylammonium bromide-capped gold nanorods to make molecular probes. Langmuir 23(17), 9114-9119 (2007).

16 Hainfeld JF, Slatkin DN, Focella TM, Smilowitz HM. Gold nanoparticles: a new x-ray contrast agent. Br. J. Radiol. 79(939), 248-253 (2006).

17 Huang X, El-Sayed IH, Qian W, El-Sayed MA. Cancer cell imaging and photothermal therapy in the near-infrared region by using gold nanorods. J. Am. Chem. Soc. 128(6), 2115-2120 (2006).

18 Huang HC, Barua S, Kay DB, Rege K. Simultaneous enhancement of photothermal stability and gene delivery efficacy of gold nanorods using polyelectrolytes. ACS Nano 3(10), 2941-2952 (2009).

19 Satija J, Bharadwaj R, Sai V, Mukherji S. Emerging use of nanostructure films containing capped gold nanoparticles in biosensors. Nanotechnol. Sci. Appl. 3, 171-188 (2010).

20 Pissuwan D, Niidome T, Cortie MB. The forthcoming applications of gold nanoparticles in drug and gene delivery systems. J. Control. Release 149(1), 65-71 (2011).

21 Dominska M, Dykxhoorn DM. Breaking down the barriers: siRNA delivery and endosome escape. J. Cell Sci. 123(Pt 8), 1183-1189 (2010).
22 Taylor A, Wilson KM, Murray P, Fernig DG, Levy R. Long-term tracking of cells using inorganic nanoparticles as contrast agents: are we there yet? Chem. Soc. Rev. 41(7), 2707-2717 (2012).

- A good paper for describing the intracellular process of nanoparticles.

23 Chithrani DB. Intracellular uptake, transport, and processing of gold nanostructures. Mol. Membr. Biol. 27(7), 299-311 (2010).

24 Chithrani BD, Chan WC. Elucidating the mechanism of cellular uptake and removal of protein-coated gold nanoparticles of different sizes and shapes. Nano Lett. 7(6), 1542-1550 (2007).

25 Pyshnaya IA, Razum KV, Poletaeva JE, Pyshnyi DV, Zenkova MA, Ryabchikova EI. Comparison of behaviour in different liquids and in cells of gold nanorods and spherical nanoparticles modified by linear polyethyleneimine and bovine serum albumin. BioMed. Res. Int. 2014, 908175 (2014).

26 Boya P, Kroemer G. Lysosomal membrane permeabilization in cell death. Oncogene 27(50), 6434-6451 (2008).

27 Zhao M, Antunes F, Eaton JW, Brunk UT. Lysosomal enzymes promote mitochondrial oxidant production, cytochrome C release and apoptosis. Eur. J. Biochem. 270 (18), 3778-3786 (2003).

28 Boya P, Andreau K, Poncet D et al. Lysosomal membrane permeabilization induces cell death in a mitochondriondependent fashion. J. Exp. Med. 197(10), 1323-1334 (2003).

29 Li H, Sun Y, Chen D et al. Synergistic anti-tumor therapy by a comb-like multifunctional antibody nanoarray with exceptionally potent activity. Sci. Rep. 5, 15712 (2015).

- A good article about the nanoantibody for immunotherapy.

30 Guicciardi ME, Leist M, Gores GJ. Lysosomes in cell death. Oncogene 23(16), 2881-2890 (2004).

31 Wang C, Wang Y, Li Y et al. A nanobuffer reporter library for fine-scale imaging and perturbation of endocytic organelles. Nat. Commun. 6, 8524 (2015).

32 Qiu Y, Liu Y, Wang L et al. Surface chemistry and aspect ratio mediated cellular uptake of Au nanorods. Biomaterials 31(30), 7606-7619 (2010).

33 Gao J, Chen H, Yu Y et al. Inhibition of hepatocellular carcinoma growth using immunoliposomes for co-delivery of adriamycin and ribonucleotide reductase M2 siRNA. Biomaterials 34(38), 10084-10098 (2013).

34 Li W, Wei H, Li H, et al. Cancer nanoimmunotherapy by advancedpharmaceutical nanotechnology. Nanomedicine 9 , 2587-605 (2014).

- A good review for introducing the nanoimmunotherapy.

35 Reers M, Smiley ST, Mottola-Hartshorn C, Chen A, Lin M, Chen LB. Mitochondrial membrane potential monitored by JC-1 dye. Methods Enzymol. 260, 406-417 (1995).

36 Smiley ST, Reers M, Mottola-Hartshorn C et al. Intracellular heterogeneity in mitochondrial membrane potentials revealed by a J-aggregate-forming lipophilic cation JC-1. Proc. Natl Acad. Sci. USA 88(9), 3671-3675 (1991). 
37 Roberg K, Johansson U, Ollinger K. Lysosomal release of cathepsin $\mathrm{D}$ precedes relocation of cytochrome $\mathrm{C}$ and loss of mitochondrial transmembrane potential during apoptosis induced by oxidative stress. Free Radic. Biol. Med. 27(11), 1228-1237 (1999).

38 Li W, Zhao H, Qian W et al. Chemotherapy for gastric cancer by finely tailoring anti-Her2 anchored dual targeting immunomicelles. Biomaterials 33(21), 5349-5362 (2012).

39 Adams JM, Cory S. The Bcl-2 apoptotic switch in cancer development and therapy. Oncogene 26(9), 1324-1337 (2007).

40 Thiery JP, Acloque H, Huang RY, Nieto MA. Epithelial-mesenchymal transitions in development and disease. Cell 139(5), 871-890 (2009).

41 Budihardjo I, Oliver H, Lutter M, Luo X, Wang X. Biochemical pathways of caspase activation during apoptosis. Annu. Rev. Cell Dev. Biol. 15, 269-290 (1999).

42 Cardone MH, Roy N, Stennicke HR et al. Regulation of cell death protease caspase- 9 by phosphorylation. Science 282(5392), 1318-1321 (1998).

-• A good article describing the caspase-9 apopotisis.
43 Porter AG, Janicke RU. Emerging roles of caspase-3 in apoptosis. Cell Death Differ. 6(2), 99-104 (1999).

44 Jaattela M, Cande C, Kroemer G. Lysosomes and mitochondria in the commitment to apoptosis: a potential role for cathepsin D and AIF. Cell Death Differ. 11(2), 135-136 (2004).

45 Du C, Fang M, Li Y, Li L, Wang X. Smac, a mitochondrial protein that promotes cytochrome $\mathrm{C}$-dependent caspase activation by eliminating IAP inhibition. Cell 102(1), 33-42 (2000).

46 Wang L, Liu Y, Li W et al. Selective targeting of gold nanorods at the mitochondria of cancer cells: implications for cancer therapy. Nano Lett. 11(2), 772-780 (2011).

47 Repnik U, Stoka V, Turk V, Turk B. Lysosomes and lysosomal cathepsins in cell death. Biochim. Biophys. Acta 1824(1), 22-33 (2012).

48 Zhang W, Ji Y, Wu X, Xu H. Trafficking of gold nanorods in breast cancer cells: uptake, lysosome maturation, and elimination. ACS Appl. Mater. Interfaces 5(19), 9856-9865 (2013). 